\title{
TECHNOLOGY ENTREPRENEURIAL ECOSYSTEMS AND ENTREPRENEURSHIP IN THE WEST REGION OF ROMANIA
}

\author{
Lecturer Alexandru Roja PhD \\ West University of Timisoara, Faculty of Economics and Business Administration \\ E-mail: rojaalexandru@gmail.com
}

(Received February 2015; accepted April 2015)

\begin{abstract}
Technical progress and entrepreneurship have become drivers of economic and social stability and progress. To develop their new ventures, to generate value, and to validate and implement business ideas, entrepreneurs need a competitive business environment, we name it technology entrepreneurial ecosystem. Entrepreneurial new ventures competitiveness depends on the entrepreneurial ecosystem structure and components. Our research presents the main levels of information technology industry linked with technology entrepreneurial ecosystems components. In the second part of our research we present the entrepreneurs perception about information technology entrepreneurial ecosystem in the west region of Romania. Our objective was to find out the entrepreneurs point of view about opportunities and influences that they perceive in the regional entrepreneurial ecosystem.
\end{abstract}

Key words: entrepreneurship, entrepreneurial ecosystem, information technology, strategy J.E.L. CODES: M10, M13, L26

\section{Introduction}

With a competitive global market and rising social challenges such as youth unemployment and ageing population, there exists opportunities to create an environment that that can add value in economy and for regional development. Entrepreneurs are a huge source of economic growth, innovation and job creation. And in Europe they represent a diverse cluster of individuals.

Entrepreneurship is among the most basic and fundamental human endeavors. Every day, people around the world seek new and innovative ways to make a living, to start a new venture, to capitalize on an idea and have a great impact in society. From hi- tech innovators to service providers, entrepreneurs' activities have a great impact and change the way in which we experiment the life. What unites them is the desire to apply their talents and available resources in the best way they can. What distinguishes them is the degree to which they can realize these aspirations depending on to the environment they operate in and innovativeness.

The importance of entrepreneurship goes beyond the immediate, individual 
achievement. If a proper supporting environment exists to productively channel the entrepreneurial spirit, such individual efforts add up to systemic impact. Entrepreneurship has the power of moving economies to new stages of development and helping societies to become more participatory, inclusive and innovative.

Entrepreneurship is at the very core of vibrant market economies. It propels innovation and growth, creates jobs, and provides consumers with new and better goods and services. Crucially, in countries whose economies are dominated by the state, entrepreneurship helps overcome dependence on government and strengthens economic and personal freedom. In so doing, entrepreneurs not only advance their own business vision but also, cumulatively, create greater economic pluralism as an alternative to centralized state control and multinational companies.

Entrepreneurship is a powerful force that many strive to harness. Countries around the world aspire to make their economies and business sectors more competitive by boosting entrepreneurship. New ways of thinking about entrepreneurship drive innovators who use business acumen to advance greater social goals. Sources of finance are becoming more accessible to start-ups than ever before. Yet in most countries entrepreneurs still struggle with the basics of operating and growing their businesses because the attention and resourced devoted to entrepreneurship promotion tend to focus on singular interventions, not systemic change.

Building a truly competitive entrepreneurship ecosystem requires an environment where businesses can operate on a level playing field, where property rights are protected, and the same rules apply to all. There is no one-size-fit-all template for building such ecosystems. While powerful examples of success stories exist, each country must find its own unique approach to reform. That requires an open dialogue where policymakers and entrepreneurs come together to discuss barriers and find solutions for sustainable development. It is not an easy process but - as examples of countries that managed to create thriving entrepreneurship ecosystems show - it can be a transformational one.

New ventures, ranging from tech start-ups to manufacturers and retailers, are pioneering new types of products and services that can add value in economy and society. Stakeholders of the entrepreneurial ecosystems must develop a willingness to develop and implement strategies to foster entrepreneurship and growth. Entrepreneurial ecosystems must provide access to financial capital and human capital, the right education and skills, a competitive business environment and clear, non-onerous regulations that does not needlessly burden business models. The economic potential of entrepreneurs can be tremendous. If this potential is properly harnessed and budding entrepreneurs provided with the skills and resources they need to build their ideas into successful businesses, the Romanian economy will flourish in future.

DE GRUYTER OPEN 
An innovation ecosystem in which entrepreneurs build their businesses refers to the combination of factors for innovation that function together in symbiotic relationships. The real-word application is the environment within which entrepreneurs function as one integral component. Value generated by new ventures has an important effect on the broader economy at regional, national and global scale.

Information technology is extremely important for social and economic development and it is the most dynamic area for entrepreneurial ideas. The importance of entrepreneurship in the field of information technology is related to the impact of technologies in economy and society. On the other side, entrepreneurs are attracted by the information technology field because the time to validate the ideas and products is short and they can go quickly on the market. In the field of information technology, human resources skills and competences are the most valuable assets, but the factor that makes the difference is innovation. Field of information technology is characterized by a very high dynamic, business start-ups emergence, and the opportunity for entrepreneurs to be competitive through a strategic approach.

Research objectives of this research paper was to analyze entrepreneurial ecosystems structure, the levels and other components and the way in which cofounders of the most important startups from the west region of Romania relate with regional technology entrepreneurial ecosystem. The research is based on two main directions as assumptions. The first line of research is based on the description of technology entrepreneurial ecosystems and its structure. We were interested to find and analyze the most important components of the entrepreneurial ecosystem in information technology industry. The second direction of research was focused on entrepreneurial strategies, entrepreneurial patterns and the way in which entrepreneurs relate with entrepreneurial ecosystems in the West Region of Romania. When entrepreneurs engage in new ventures in the regional ecosystem, they found few reference points by which to start and grow a start-up, a lack of support services to understand the steps and the skills they need in entrepreneurship and business management. For that it is important to understand the way in which entrepreneurs relate to all the contingency factors that can shape or affect their business strategy.

\section{Information technology sector main levels and intersections with technology entrepreneurial ecosystems}

Information technology industry has been in constant evolution over time and the most important changes they underwent were determined by the entrepreneurial innovations and by the social progress that has generated new needs in society. As 
evolution, over time, we can distinguish several important stages of information technology industry, which is its most important cycles: the time of the first innovations in the field of information technology and first personal computers, between 1970 and 1995; pre-Internet and Internet bubble between 1995 and 2000; users' needs centered technology between 2000 and 2010; cloud computing and Internet of Things from 2010 to present time. Information technology sector in most advanced countries is one of the largest in the economy with a rate of over $10 \%$ of GDP. The contribution of technology to economic growth is more important, because the complementarity of the business sectors. Information technology is the foundation of development, efficiency and productivity of the developed economies. According to OECD statistics, over 20\% of the growth is due to the information technology sector and one third to research and development that takes place in business sectors (OECD, 2014).

Information and communication technology provides fundamental and ubiquitous infrastructure for a modern economies and societies, facilitating the processing, storage and transmission of information. Identifying the main components that are part of a technology ecosystem is a difficult task because the dynamics of the field of information technology is extremely high. The life cycle of high-tech products was shortened considerably over time. Competitiveness of information technology companies is correlated with innovation and with products and services portfolios development.

An important thing to consider is the behavior and strategies of technology companies. The field of information technology is relatively new and some companies have developed new niches. The dynamics of information technology sectors is determined by leading technology companies' capacities and capabilities to set the trends. Therefore, the dynamics of the whole sector can be correlated with the strategies of the main players in the field of information technology. Information technology industry is composed by several levels, each with different characteristics and there is also interdependence and relationships between these levels. Entire industry dynamics is related to relationships between his constituent elements. Information technology industry is both technological architectures or engineering structures and economic and institutional models and structures. It consists in specific architectural engineering, equipment's, technologies, information resources and economic components like business sectors, markets, organizations and economic services whose operations is based on information technology, and institutional framework that regulates and defines business environment. Technology ecosystems should be viewed in terms of the functions it performs and its functionality. Technology industry where entrepreneurial ideas become businesses is a modular system in terms of technical and technological engineering sciences, which is defined by a variety of technological architectures, 
and from the economic perspective a variety of organizational forms.

A technological industry on which technology entrepreneurial ecosystems can emerge consists of for main groups of components as follows:

- Level 1: interconnected equipment's and elements, computers, mobile devices, network equipment

- Level 2: communication and telecommunication networks

- Level 3: platforms, applications and content

- Level 4: users and clients of technology ecosystem

At all levels we have a variety of elements that are interdependent and connected. Information technology industry is regulated by laws and rules and these regulations are country specific. The development of technology entrepreneurial ecosystems levels is correlated with the degree of regulations and governmental strategies. Also, the degrees of technology industry levels development greatly influence consumer behavior and trends. Competition and innovation are determinants of the direction in which each level which forms the technology industry will evolve in the future. A technological industry is defined by the nature of the relationships and connections between components arising and its levels.

The first level of information technology industry is a fundamental one and brings together all equipment, components, computer systems, network equipment, mobile phones, tablets and other devices that generate, access and process information. The principles that govern our economy in this time are based on networks, relationships and interconnected resources. It is a trend to integrate all equipment's and resources in global networks. The next-generation networks will be the Internet of things, cloud computing and big data infrastructures. All this trends will transform the businesses and social life.

Items of the first level are interconnected at the second level. At this level we find communication and telecommunication networks, which ensures the integration of fixed and mobile components and equipment's of the first level and information transmission between them.

Communication and telecommunication networks and services are key components of industry because provide the ubiquity of information. The second level of technology industry can be regulated by governmental and institutional rules and laws. In the first stages of the emergence and development, these networks were separated by standards and by different needs addressing on the market. In the first period of their emergence, communication networks have been unbundled by telephone networks, cable television and satellite networks. In the last decade we have seen a tendency to unify the networks, communication services. The services become substitutable or complementary and was adopted a strategy of unification of the technological standards and protocols. The convergence of technologies and 
standards generate a profound change in the technology industry. The impact of technology products and services in economy and society is much higher and competitiveness of technology companies increase steadily. The greater the number of users in a network, the lower will be the operating costs. The network effect increases the network capacity expansion and thus increases revenue. Therefore, at this level of technology industry have developed with a greater extent those companies who have been privileged by dominant position on the market.

On the second level of the technology ecosystem we can find also a very important component, especially if we consider that the main role of the industry is to provide access to information. In the technical literature we can found the concept of "middleware" which means those applications and services which provide the possibility to use and manipulate information, that assure the connections between databases and knowledge, and operating system interfaces to provide users access, storage capacity and information processing systems. Basically, what we meant by "middleware" is a bridge between information owners and users through communication networks and computing systems.

It is important to note that the third level of technology industry acts as a veritable platform for innovation. At this level we can see entrepreneurial initiatives, many of them innovative with high impact in economy and society. The initial investment required to start a business at this level of ecosystems is not very high and investment funds have a high interest to support entrepreneurs who have innovative ideas for products and services. Products and business models can be validated and scaled easier on the third level and for an entrepreneur this is very important. Another argument that we can bring to the attractiveness of this level, is that entrepreneurs are in a direct relationship with customers by understanding the trends and needs of society. We are currently witnessing a trend of increasingly high technology role in human life. Technology is responsible by a big part of the business and human activities. Augmented reality, extending human senses and information ubiquity, as technology trends have led to an increased interest of entrepreneurs to start new ventures, and the development of a large number of applications. With the support of Internet service providers, middleware platforms came to be used on a global scale. Major global technology companies have built their platforms and standards for online content and services using the Internet infrastructure and services from the second tier of technology ecosystem, as well as applications and resources from the third tier.

The concepts like content, applications and services are the essence of social and economic activities and outputs that are generated through the use of technology. The concept of content refers to information provided by networks, by global Internet network or stored on various media. An application means a program or group of programs designed and used by users, which include a number of features. 
The fourth level of the information technology industry includes all users who often identify with the end users and customers of the other three levels. Customers have a major role in the industry and companies have redefined the business strategies focusing greater on customer relationships and their experiences. This strategic shift has been driven by the dynamics of business sectors and by the increasing role of innovation to gain competitive advantage.

There are two facets of the causes that led to changes in specific technology industries, namely the processes that generate variety and the selection alternatives within variety. Schumpeter considered the changes taking place in capitalism are generated by the four forms of innovation: new or improved products and services, new processes or production methods, new forms of organization and development of new markets.

The effects of symbiotic relationships arising between the four pillars that make up a technology industry are embodied in what is today the impact of information and technology in society and in economy. Globalization trends would not have been possible without the support provided by information technology and communications networks. Changes in social and business activities, generated by increasing role of information are made possible by the smart devices, by the capacity of increasingly large communications networks and by new innovative platforms that are promoting Internet of Things principles. Technology has profoundly changed the way in which entrepreneurs and organizations carry out their activities.

\section{Technology entrepreneurial ecosystem}

The most important function of entrepreneurs, according to Schumpeter is to reform or to reinvent the way in which value is generated by exploiting inventions and innovations. Business environment is characterized by globalization, increasing use of knowledge and increasing role of innovation in regional innovation systems. Technology entrepreneurship has an increasing role in the wealth creation and all this could generate the emergence of new types of entrepreneurial ecosystems (Camagni, 1995; Feldman, 1994; Porter, 1990). The reason why some regions are more advanced than others lies in successful use of new technologies and entrepreneurship fostering in information technology.

The concept of "ecosystem" originated from ecology and biology, having first been used in print by Tansley, who stated that organisms cannot be separated from the environment of the biome - the habitat factor in the widest sense with which they form one physical system (Tansley, 1935). Willis provides a contemporary definition of an ecosystem. He consider that as a concept an ecosystem is a unit comprising a community, or communities of organisms and their physical and chemical environments, at any scale, desirably specified, in which there are 
continuous fluxes of matter and energy in an interactive open system (Willis, 1997). In economy, 1990 James Moore created in 1990 the strategic planning concept of a business ecosystem. He defines it as an economic community supported by a foundation of interacting organizations and individuals, producing goods and services of value to customers, who are themselves members of the ecosystem. The member organisms also include suppliers, lead producers, competitors, and other stakeholders. Over time, they coevolve their capabilities and roles, and tend to align themselves with the directions set by one or more central companies (Moore, 1996).

Related to Therin there are several words and definitions used in scientific articles for entrepreneurship in the field of technology as technology entrepreneurship, technical entrepreneurship, techno-entrepreneurship and technology entrepreneurial ecosystems (Therin, 2007). Dorf and Byers, the most cited authors, define technological entrepreneurship as a style of business leadership that involves identification and human resource high-potential capitalization, technologyintensive commercial opportunities, managing accelerated growth and significant risk taking (Dorf and Byers, 2005). In their definition Shane and Venkataraman consider that technological entrepreneurship is a process of assembling resources, technical systems and strategies by a new entrepreneurial venture to pursue opportunities (Shane and Venkataraman, 2004).

Any ecosystem involves a number of interconnected key elements that constantly interact and mutually reinforce. Entrepreneurship ecosystem is no different in how it encompasses a number of moving parts - components that have to come together to facilitate innovation and growth. While different models exist, the following two examples illustrate the common emerging way of thinking about entrepreneurship ecosystems structure.

Daniel Isenberg, outlines six key components of the entrepreneurship ecosystem: conducive culture, enabling policies and leadership, availability of appropriate finance, quality human capital, venture-friendly markets for products, and a range of institutional and infrastructural supports. These domains in turn group hundreds of smaller elements. Isenberg emphasizes that even though any country's entrepreneurship ecosystem can be mapped out using the same domains, each such ecosystem remains unique because it is a result of hundreds of elements interacting in complex ways. These factors are based in historically shaped institutions that give different countries and regions unique competitive advantages but also unique sets of challenges to overcome in order to become more entrepreneurship friendly. That is why it is usually ineffective to simply take one country's model of entrepreneurial development and blindly apply it to another. Successful models are useful, but each country must find its own way. Each country instead must examine its own circumstances, strengths, and weaknesses and design approaches that are

DE GRUYTER OPEN 
rooted in these local realities (Isenberg, 2011).

Steven Koltai, who created and ran the Global Entrepreneurship Program for the U.S. Department of State, provides another example of mapping out core components of entrepreneurial ecosystems. The Six + Six Model highlights the six pillars essential to a successful entrepreneurial ecosystem: identify, train, connect $\&$ sustain, fund, enable, and celebrate entrepreneurs; and the six participants who must be involved in their implementation: non-governmental organizations, corporations, foundations, government, academic institutions, and investors.

Similarly to Isenberg's approach, Koltai's model rests on the premise that no single factor alone can spur and sustain entrepreneurship. Instead, entrepreneurs thrive when multiple sectors and actors work together to create a supportive environment for entrepreneurship. In Koltai opinions the interconnectedness of all the elements of the entrepreneurship ecosystem is very important, and stresses the need for various actors to work together in order to promote entrepreneurial culture. He also emphasizes that it is a mistake to think of entrepreneurs purely as inventors of new products, and point out the business skills for entrepreneurs. In fact, only a small part of entrepreneurs are innovators in that narrow sense and other part are commercializes who bring new ideas to market. Therefore, the vast majority of successful entrepreneurs did not think of their innovation, which can be a new product or process, but rather thought of a way to make somebody else's innovative idea reality. Only a small part of entrepreneurs think to relation between innovation and entrepreneurship as added value for economy and society. The inventors are then flooded with funds but they do not receive enough education, mentorship, and other forms of support needed to make their idea commercially viable. Countries need to consciously build regional or national ecosystems that help these different kinds of entrepreneurs succeed.

We can analyze technology entrepreneurial ecosystems or technological entrepreneurship at many levels and from interdisciplinary perspectives. We have identified non-entrepreneurial factors and entrepreneurial factors that define technology entrepreneurial ecosystems. The difference between entrepreneurial and non-entrepreneurial factors is that they interact, and define entrepreneurial ecosystem, but only entrepreneurial factors are direct related to entrepreneurs and their behavior. Non-entrepreneurial factors are: start-ups, markets, infrastructure, innovation systems, government \& regulations and regional factors. Entrepreneurial factors are education, entrepreneurial culture, support services, promoting and visibility, networks, communities, advisors, incubators, accelerators, hubs, capital and financing. 
Roja, A., (2015)

Technology entrepreneurial ecosystems and entrepreneurship in the west region of Romania

\section{Table 1. Non-entrepreneurial factors of technology entrepreneurial ecosystems}

\begin{tabular}{|c|c|}
\hline \multicolumn{2}{|l|}{ NON-ENTREPRENEURIAL FACTORS } \\
\hline Regional factors & Markets \\
\hline $\begin{array}{l}\text { cost of living } \\
\text { services } \\
\text { taxes and logistic facilities for companies } \\
\text { economic agglomeration } \\
\text { clusters } \\
\text { collaborative networks } \\
\text { regional innovation systems }\end{array}$ & $\begin{array}{l}\text { customers } \\
\text { early adopters } \\
\text { suppliers } \\
\text { competitors } \\
\text { distribution channels } \\
\text { large companies as strategic partners } \\
\text { new entrants } \\
\text { substitution products }\end{array}$ \\
\hline Infrastructure & Innovation system \\
\hline $\begin{array}{l}\text { ICT infrastructure } \\
\text { telecommunication and communication networks } \\
\text { physical and roads infrastructure } \\
\text { universities } \\
\text { research centers } \\
\text { logistics } \\
\text { working spaces }\end{array}$ & $\begin{array}{l}\text { intellectual property } \\
\text { technology transfer } \\
\text { research and scientific development } \\
\text { knowledge } \\
\text { skills and abilities } \\
\text { innovation culture }\end{array}$ \\
\hline Government, policy and regulations & Start-ups \\
\hline $\begin{array}{l}\text { strategies and policies to foster information } \\
\text { technology industry } \\
\text { strategies for regional development } \\
\text { property rights } \\
\text { degree of complementary business sector } \\
\text { development } \\
\text { labor law }\end{array}$ & $\begin{array}{l}\text { number of young companies } \\
\text { dynamics of startups } \\
\text { maturity of companies } \\
\text { entrepreneurial spirit } \\
\text { serial entrepreneurs }\end{array}$ \\
\hline
\end{tabular}

Source: author view

The most important component of technology entrepreneurial ecosystem is the entrepreneur itself, he and his vision are the keys catalysts in the process of business sectors emergence and start-ups growth.

Technology entrepreneurs have more technical skills and competences than nontechnical ones, and they have to acquire also business and managerial skills in the process of business growth and competitiveness.

One important step in the new venture success is the transformation of the entrepreneurial mind into managerial one. The business and tasks will become more complex and entrepreneurs have to understand the business environment and contingency factors, and they need a vision and a strategy to foster the competitiveness of the new venture. 
Roja, A., (2015)

Technology entrepreneurial ecosystems and entrepreneurship in the west region of Romania

Table 2. Entrepreneurial factors of technology entrepreneurial ecosystems

\begin{tabular}{|c|c|}
\hline \multicolumn{2}{|l|}{ ENTREPRENEURIAL FACTORS } \\
\hline Education & Entrepreneurial culture \\
\hline $\begin{array}{l}\text { educational programs in entrepreneurship } \\
\text { skills and abilities } \\
\text { certification } \\
\text { mentors }\end{array}$ & $\begin{array}{l}\text { risks taking } \\
\text { entrepreneurial mindset } \\
\text { creativity } \\
\text { ambition and determination } \\
\text { tolerance of failure and risks } \\
\text { role models } \\
\text { social status of entrepreneurs } \\
\text { success culture }\end{array}$ \\
\hline Support services & Promoting and visibility \\
\hline $\begin{array}{l}\text { legal, accounting and financial } \\
\text { business and management } \\
\text { marketing } \\
\text { coaching } \\
\text { advisors, experts and consultants } \\
\text { labor and talent management } \\
\text { export and taxes } \\
\text { foundations }\end{array}$ & $\begin{array}{l}\text { tech meet-ups } \\
\text { business meet-ups } \\
\text { events } \\
\text { conferences } \\
\text { hackathons } \\
\text { business ideas contests } \\
\text { entrepreneurship and startup websites } \\
\text { awards }\end{array}$ \\
\hline Networks & Communities \\
\hline $\begin{array}{l}\text { collaborative networks } \\
\text { informal networks: groups, entrepreneurs } \\
\text { networks } \\
\text { formal networks: institutions, organizations, } \\
\text { associations, agencies, alumni groups } \\
\text { other groups }\end{array}$ & $\begin{array}{l}\text { regional or national technical communities } \\
\text { business communities } \\
\text { users communities }\end{array}$ \\
\hline Capital and financing & Incubators, accelerators and hubs \\
\hline $\begin{array}{l}\text { business angels and venture capitalists } \\
\text { private equity } \\
\text { micro financing } \\
\text { seed funding } \\
\text { loans and debts } \\
\text { crowd funding }\end{array}$ & $\begin{array}{l}\text { acceleration programs } \\
\text { incubation programs } \\
\text { co-working space and hubs }\end{array}$ \\
\hline
\end{tabular}

Source: author view

Technology entrepreneurs have to understand the trends and the development of the new venture, and also the importance of managerial skills in business administration process. Success for technology entrepreneurs depends on the strategic oriented mindset. The most important three motivational factors of the technological entrepreneurs are independence, opportunities exploitation and value generation (Oakley, 2003). In information technology industry, the networks 
between entrepreneurs are enhancers of business life cycle stages. Continuous learning is important for entrepreneurs and also for managers because they need to develop their skills and competences. Educational institutions as components of the entrepreneurial ecosystems provide the needed educational services. The most important role of universities is the educational one as a supplier of qualified workforce. Universities can act as a node in the networks between corporations, incubators, research centers, clusters and technology parks. Universities have also an important role of spin-offs generators, when research products or knowledge generate values in business environment.

Collaboration between universities, research centers, start-ups incubators, corporations, small and medium enterprises and other regional entities is very important to foster innovation, know-how transfer and human resource development. At the regional level, clusters as a form of collaboration between companies can increase competitiveness of start-ups, and have positive effects on innovation and long term development. The main role of technological parks, incubators, accelerators and hubs is to ensure and enhance collaborative and interconnected environment which increase interaction between communities, resources, ideas and technologies.

Entrepreneurial approaches in information technology industry have become important sources of value generation and growth in Europe due to the dynamics and the value that information technology brings in our daily life and in business. Developed countries have realized the major role that information technologies have in society and in economy. Technology can be harnessed by strategies that encourage, ensure and accelerate the creation of start-ups in information technology field. Currently techno-entrepreneurship promises both high profits and high risks for founders and investors.

For entrepreneurs one of the biggest challenges is to validate the value of opportunities and business idea before its realization. The main goal of the entrepreneurial approach is to create and capture economic value either by developing new technologies or by exploiting them. To achieve these goals, entrepreneurs must develop strategies and business models to recreate new dimensions of socio-economic life beginning from ideas and strategic vision.

The ability to recognize business opportunities is a major skill an entrepreneur should acquire and it will dramatically shape the future of his venture. To our view, despite a thorough understanding of the opportunity recognition process, its determinants of success and failure, quite an important lack of understanding remains as to appropriate anticipative and proactive approaches. The literature in the fields of management and entrepreneurship assumes that entrepreneurs are able to anticipate, to be proactive and to build a credible vision of their business. Proactive thinking is an important ability of entrepreneurs. They need to

DE GRUYTER OPEN 
understand the business environment and the influences of entrepreneurial ecosystem components to new venture strategies. Proactive management enables entrepreneurs to understand and to exploit the first signs of changes and to develop strategies to minimize risks and maximize competitive advantage of their businesses.

Counteracting and minimizing specific risks and negative influences of business environment dynamics require proactive entrepreneurial strategies and plans deployments to make startups competitive, or to increase the competitiveness of existing ones. The relations between entrepreneurs and entrepreneurial ecosystem components are particularly important in the light of opportunities identification, information and knowledge acquired and conceptualization of future business value. Schumpeter (1976) put the emphasis on entrepreneurs as those who, in opposition to traditional capitalists, engage in new activities or ventures that did not exist before and in innovative or creative ones. A Schumpeter view on entrepreneurship is that entrepreneurs have to explore new opportunities in order to build a new world order while deconstructing or destructing the old one. Entrepreneurship can be defined as an activity and a process involving the discovery, creation and exploitation of opportunities in order to create value thanks to the introduction of new goods, services, processes and organizations (Therin, 2007).

The way individuals recognize opportunities for business creation is one of the first critical abilities in the early stages of the business development process. Entrepreneurs have to be those people who sense, create and respond to changes and needs regarding a possible opportunity for profit. The literature review highlights different approaches of entrepreneurship. Davidson (2004) argue that in practice we can identify in entrepreneurial ecosystem three main streams of thinking about the nature of an opportunity: the objective approach in which opportunities do exist in the environment so that entrepreneurs can identify them and build a strategy to capitalize them; the subjective objective approach focusing on the ability and individual characteristics of entrepreneurs; and the subjective creative approach where the opportunity is built in the mind of the entrepreneurs using creative thinking.

If we consider that technology is at the core and origin of the new venture we will refer to technology based-entrepreneurship. We have identified many authors that paid attention to the concept of innovative entrepreneurship related to new technologies development. Gaglio, De Koning, Singh and Therin argue that entrepreneurship and opportunities are a social construct and correlated with entrepreneur values, behavior cognitive capabilities, knowledge, competence, skills and connections with entrepreneurial ecosystem and individual motivations (Gaglio, 1997; De Koning, 1999; Singh, 1999). 
Technology based entrepreneurship brings in more novelty, innovations and R\&D products on the markets. If technology is involved, entrepreneurship consists in bringing important changes into the traditional markets and in society compared to the more traditional entrepreneurship.

For entrepreneurs in the field of technology, opportunity recognition starts with the sensing of a need or a change and ends with innovative solutions in which future potential economic value is validated and recognized. The new venture will generate value for stakeholders and owners if the founder will understand the entrepreneurial ecosystem. Information's and knowledge should have been gathered in order to answer key issues regarding business model, new venture and markets. Techno-entrepreneurs will have to undergo a series of other activities, non-technical ones related to management, including creative thinking, incubating, demonstrating, validating, promoting and sustaining (Jolly, 1997). Entrepreneurs can extend their knowledge about technology, entrepreneurship, managerial skills and competences through their professional, and all these are limited by their absorptive capacity and ability to understand the entrepreneurial ecosystem. Techno-entrepreneurs will draft and redraft their vision and strategy linking the opportunities with business environment and startup capabilities. Proactive entrepreneurs will understand the business environment opportunities, risks and will innovate their business models, products or services to become competitive. Collaboration in entrepreneurship is very important because synergies and complementarity can make a new venture competitive in the field of very expensive resources. Technology parks can bring together entrepreneurs or startups with distinctive and complementary capabilities. The main role of technological parks is to interconnect components like communities, universities, governmental agencies and institutions, resources and to foster innovation through collaboration. The most important objectives of technological parks are: to foster innovation and collaboration, to be an interface between science and business environment, to generate value in regional economy, and to provide technical and business consulting services. For entrepreneurs in the field of technology it is important to understand not only the changes in business environment but also to promote change in their organizations. A survey made on more than 200 Romanian organizations according to the respondents that participated to this study in $72 \%$ of the cases change comes from external sources and only 28 from within organizations (Prediscan \& Roiban, 2014). We conclude that he driving forces of entrepreneurial ecosystems can generate change in technology startups.

Corporations have also an important role in technological ecosystems. In addition to the innovative character of corporate entrepreneurship initiatives in large, medium and small companies can generate spin-offs when employees decide to use their skills and know-how into a new start-up venture.

DE GRUYTER OPEN 


\section{Technology entrepreneurship in the West Region of Romania}

Our research was conducted in the West Region of Romania. This research followed two main directions. The main direction of research was focused on the perception that entrepreneurs have about information technology regional entrepreneurial ecosystem. We wanted to find out the perception that entrepreneurs have about opportunities and influences that they perceive in the regional entrepreneurial ecosystem. Our research is based on the administration of twenty interviews with cofounders of the most important information technology start-ups and companies in the region of western Romania. Questionnaires containing thirty questions were administered via interviews. Interviews were conducted during the end of 2014 and respondents were entrepreneur's founders of companies.

The first important objective of our research was to examine how entrepreneurs relate to regional entrepreneurial ecosystem. Entrepreneurial ecosystem through its components should support the emergence and development of startups, internationalization and providing resources for business growth. In this research we will examines the way that entrepreneurial ecosystem influence startups, entrepreneurial thinking and business strategies. The way that entrepreneurs relate to entrepreneurial ecosystem is different and depends heavily on their experience in the business. On the one hand, entrepreneurs with experience deeply understand the entrepreneurial ecosystem components and the links between them. Less experienced entrepreneur's relates differently, being more oriented on the opportunities and the need to validate business ideas, and finding the best source for financing business growth stages.

One of the most important components in the entrepreneurial technology ecosystem is practitioner's communities. We were interested to examine the involvement of entrepreneurs in these professional communities and how they perceive the opportunities provided by ecosystem in western part of Romania.

Most of interviewed entrepreneurs stated that they are actively involved in the professional communities, regularly participating at events conducted by them. Communities are groups of professionals bringing together professionals with a high degree of specialization in different fields of technology. Some interviewed entrepreneurs were drawn from these communities setting up their own start-ups. Participating at events held by communities was an opportunity to find co-founders for the new venture, especially access to human resources with high level of specialization.

Most entrepreneurs consider extremely important the role of communities in bringing together professionals with a high degree of specialization in different areas of information technology. An essential role of professional communities in the West Region of Romania is to encourage the exchange of information, know- 
how, access to new technologies and trainings of future specialists. These communities do not encourage competition, but the exchange of information and knowledge through collaboration. There are startups that are part of more extensive networks with a more complex form of organization as Regional Information Technology Cluster which offers many benefits to its members. Five of the twenty entrepreneurs interviewed stated that interaction with regional entrepreneurial ecosystem is limited to qualified human resources and highly specialized professionals. The first negative aspect noted is that the entities of entrepreneurial ecosystem in the West Region of Romania does not sufficiently promote entrepreneurial culture and does not promote collaboration among ecosystem components. Also the entrepreneurial ecosystem don't help startups to become more competitive in a broader context.

This view was reinforced by other entrepreneurs who find it difficult to conduct business in the current regional entrepreneurial ecosystem. They believe that there are socio-cultural aspects which are threats or challenges for entrepreneurs and startups especially for collaboration. Individualism that characterizes entrepreneurs in the region inhibits collaborative relationships and common goals settings. Entrepreneurs who own companies in the growth phase of the life cycle were able to establish relationships with other companies to carry out joint projects. More specifically, for not losing skilled employees, there are companies that work together and collaborate in regional entrepreneurial ecosystem.

Another important aspect to note which is linked to regional technology ecosystem is that in the west region there are many large companies that have taken over a part of information technology professionals. These large companies prefer to act independently. One way that might exploit in a greater manner the potential and flexibility of innovative startups would be that multinationals acting as nodes in collaborative partnerships and in complex projects where startups are involved.

Most entrepreneurs believe that one of the most important component of the entrepreneurial ecosystem has been the business incubator which host startups and companies operating in the software industry and whose foundations were laid by the Polytechnic University of Timisoara. Entrepreneurs interviewed claim that the benefits brought by business incubator are of two types. Business incubator provided a range of facilities which cut the operational costs for startups. Another benefit was perceived by entrepreneurs as access to resources and a large business and professional network through which start-ups have become visible in a broader context.

Entrepreneurs who have reached the first growth stage, believes that most of the actions initiated by the major regional entities of the entrepreneurial ecosystem are only likely administrative not strategic one. They said that at the regional level strategies to increase competitiveness of startups in some high specialized fields of 
information technology are not clearly defined. Entrepreneurs believe that the most successful initiatives that can support the collaborative association of entrepreneurs in the entrepreneurial ecosystem are bottom-up arising from the vision, the will and the involvement of entrepreneurs and not as a consequence of the top level agencies or institutions which are catalyst in the entrepreneurial ecosystem. Entrepreneurs argue that some of top-down initiatives and strategies are useful because creates a common space for interaction between entrepreneurs and businesses. Entrepreneurs said that they would work with other local concurrent startups to benefit from greater opportunities at global level and to minimize risks. We concluded that there is a very large need at ecosystem level for innovation and to conduct joint research and development project aimed to increase competitiveness and international visibility. Also the first direction of research was focused on the perception of entrepreneurs about the opportunities provided by entrepreneurial ecosystem where startups were initiated and in which they operates. Half of the entrepreneurs interviewed are considering that they don't see opportunities provided by entrepreneurial ecosystem in West Region of Romania and they have to look for opportunities abroad. Entrepreneurs say that their companies are contacted more often by large companies from abroad seeking specific skills, especially to outsource a part of larger projects they carry out. The other halves, especially those who are owners of emergent startups, argue that they benefit from opportunities provided by regional entrepreneurial ecosystem. Competitive startups have support of Information Technology Regional Cluster. About the opportunities offered by regional ecosystem entrepreneurs consider that at the regional level the unique opportunity is the high capacity of universities to provide human resources trained in various fields. Although there are many competent human resources in the region, but multinationals employ a large number of professionals, with the possibility of relocation and labor migration. A general view of the interviewed entrepreneurs is that government has developed competitive strategies to increase the dynamic of information technology sectors but the profit margin is very low for startups.

All surveyed entrepreneurs believe that the events organized by the main actors in the entrepreneurial ecosystem are very useful for establishing new contacts, facilitating the know-how transfer, contributes to more easily identification of non tech specialists in the field and to identify the most appropriate sources of funding. Experienced entrepreneurs in the field conclude that in Romania there is no technological entrepreneurship in the true sense of the word, and the regional tech entrepreneurial ecosystem don't have yet the potential to validate, sustain and develop business ideas in information technology. Since information technology sector is extremely dynamic it is important for organizations to become or to remain competitive, and entrepreneurs must consider the sustained development of 
professional and personal skills and competencies of its employees. In this respect, entrepreneurs believe it would be useful to organize technical training to obtain qualifications and non-technical to acquire entrepreneurial and managerial skills needed in interaction with other employees. To be credible in front of a strategic client, a company must develop and upgrade skills, competences, know-how and receive certifications in the most advanced technology fields. Trainings and certification programs are considered guarantees for startup competitiveness. Most entrepreneurs believe that their companies could develop competitive strategies that would benefit from leading specialists. We conclude that the entrepreneurial ecosystem need to certify skills acquired in information technology, and develop entrepreneurial and management skills. The interviews have revealed the entrepreneurs' perceptions about the lack of vision and strategies to define a technology entrepreneurial ecosystem. Entrepreneur's view was that the lack of education, poor entrepreneurial culture, and lack of business knowledge could be sources of low level competitiveness. All interviewed entrepreneurs agree that it is extremely useful and important to take their businesses to the successive stages of growth.

All interviewed entrepreneurs believe that involvement in the development of entrepreneurial ecosystem is critical, and some of them said they are actively involved. When we asked entrepreneurs how they relate to entrepreneurial ecosystem, they talk about communities and events held by the main actors that aim to generate cohesion between ecosystem individuals and groups, identifying and attracting human resources and in some cases about mentoring.

Entrepreneurs opinions about the entrepreneurial ecosystem are that, in general provide a little help in the phase of business emergence. A positive component of ecosystem was the software incubator UBIT from Polytechnic University where most entrepreneurs have started their new ventures, but the access criteria were not based on performance or strategic vision. Because entrepreneurial ecosystem does not offer many opportunities, entrepreneur's main purpose was the visibility of their businesses and increasing the capability of business development. They argue that most initiatives from regional actors should establish strategic direction of the ecosystem, and that strategies do not exist in practice, but are merely administrative in nature. The ecosystem don't have a strategy through which start-ups can specialize and provide services and products in areas with high degree of specialization.

That specific information technology entrepreneurial ecosystem in western Romania is one emerging, and components like start-ups accelerators, consultancy services, financing and synergies between components are missing. Entrepreneurs understand that although their businesses can become competitive because products and services are demanded by the market, but it is extremely difficult for 
a start-up to become competitive at a larger scale. For an entrepreneur it is important to validate the business idea before new venture starting and to find the most appropriate ways to scale the business. In this respect, freelancers try to create a large enough customer base to support business development.

\section{Conclusions}

In this research we were interested to identify several important components of the information technology entrepreneurial ecosystems that contribute to the emergence and development of startups. Also, we were interested to find out how entrepreneurs have initiated startups in the West Region of Romania, and how this emergence relates to entrepreneurial ecosystem components. From research conducted, we conclude that entrepreneurs relate with entrepreneurial ecosystems in a narrow way. More than that, all entrepreneurs claim that the West Region should have a strategy through which all the ecosystem components to be interconnected to support entrepreneurial initiatives. We can also conclude the fact that the ecosystem needs a strategy that represents a foundation for emergence and development of new startups, and also to increase competitiveness through innovative new ventures. Also entrepreneurs with experience and business founders understand the need to change their business vision and look forward in a strategic manner. This transformation is driven by business refocus from outsourcing to products or services innovation. Entrepreneurs with experience in business understood that strategic vision and strategic management are required in high competitive business environment. Ecosystems oriented to high dynamic markets and who owns resources, capabilities and unique potential can become visible at a larger scale or even global. A regional ecosystem with vision and strategy will be competitive and able to exploit the region's resources and entrepreneurial potential. Synergies that occur in the entrepreneurial ecosystem can support emerging and new ventures development and can improve competitiveness through uniqueness and distinctiveness.

This work was co-financed from the European Social Fund through Sectorial Operational Program Human Resources Development 2007-2013, project number POSDRU/159/1.5/S/134197 ,Performance and excellence in doctoral and postdoctoral research in Romanian economics science domain"

\section{References}

1. Camagni, R.P. (1995). The concept of innovative milieu and its relevance for public policies in European lagging regions, Papers in regional Science, 74, 317 400

2. Davidsson. P. (2004). Researching Entrepreneurship, New York, Springer 
Technology entrepreneurial ecosystems and entrepreneurship in the west region of Romania

3. De Konig, A. (1999). Conceptualizing opportunity formation as socio-cognitive process, INSEAD

4. Dorf, R.C. \& Byers, H.T. (2005). Technology Ventures: from Idea to Enterprise, New York, McGraw-Hill

5. Feldman, M.P. (1994). The university and high-technology start-ups: the case of Johns Hopkins University and Baltimore, The Economic Development Quarterly, $8,67-76$

6. Gaglio, C.M. (1997). Opportunity identification: review, critique and suggested research direction, Advances in Entrepreneurship, firm Emergence and Growth, Volume 3, Greenwich

7. Isenberg, D.J. 2010. How to start an entrepreneurial revolution. Harvard Business Review 88(6): 41-49

8. Jolly. C. (1997). Commercializing New Technologies: Getting from Mind to Market, Boston, Harvard Business School Press

9. Moore, J.F. (1996). The death of competition: leadership and strategy in the age of business ecosystems, HarperBusiness New York

10.Oakley, R.P. (2003). Technical entrepreneurship in high technology small firms: some observations on the implications for management, Technovation, 23, 679-88

11.OECD (2014). Entrepreneurship at a Glance, Paris

12.Porter, M.E. (1990). The Competitive Advantage of Nations, London, Macmillan

13.Prediscan, M., Roiban, R. (2014). Achiving succesful change within Romanian orgaizations. Proceedings of Multidisciplinary Academic Conference on economics, Management and Marketing

14.Schumpeter, J.A. (1976). Capitalism, Socialism and Democracy, New York, Harper and Row

15.Shane, S. \& Venkataraman S. (2004), Guest editors introduction to the special issue on technology entrepreneurship, Research policy, 32, 181-4

16.Singh, R.P. (1999). Opportunity recognition through social network characteristics of entrepreneurs, Frontiers of Entrepreneruship Research, Wellesley

17.Tansley, A.G. (1935). The use and abuse of vegetational concepts and terms. Ecology 16, 284-307

18.Therin, F. (2007). Handbook of Research on Techno-Entrepreneurship, Cheltenham, Edward Elgar

19.Willis, A.J. (1997). The ecosystem: an evolving concept viewed historically. Functional Ecology 11, 268-271 